\title{
Critical Multiculturalism and the Politics of Identity in Academic Writing
}

\author{
Setiono Sugiharto \\ English Department, Faculty of Education, Atma Jaya Catholic University, Jakarta, INDONESIA \\ e-mail: setiono.sugiharto@atmajaya.ac.id
}

\begin{abstract}
This article discusses the critiques of critical multiculturalism of the well-established notion of liberal multiculturalism. Drawing insights from a critical theory, critical multiculturalism attempts to challenge and deconstruct the basic constructs such as culture and knowledge from the perspective of liberal multiculturalism. From this line of inquiry, I proceed to argue that English language education in the Indonesian context still clings to the spirit of liberal multicultural orthodoxy, which is evident from the English pedagogy policy, teaching and research. I then suggest that by adopting a critical perspective of multiculturalism, and hence critical multiculturalism as a framework of thinking, we can help raise teachers' awareness to adopt critical teaching and research practices that not only value the multiplicity of students' cultures but also resist linguistic and cultural determinism prevalent especially in academic writing practice. To demonstrate the possibility of resistance against the hegemonic forces of linguistic and cultural determinism, I present case studies of multilingual student writers in their search of the politics of identity in academic writing.
\end{abstract}

Keywords: Critical multiculturalism, liberal multilingualism, English language education, Indonesian context, linguistic and cultural determinism, politics of identity.

\section{INTRODUCTION}

The notion of multiculturalism has recently been challanged due to its fragile assumptions that tend to connote a sense of anglocentricity, which is defined as "the practice of judging other cultures by the standard of one's own" (Phillipson, 1992, p. 47). So understood, the notion is susceptible to abuse (either explicitly or implicitly) especially by those belonging to the so-called "dominant" or "superior" cultures. As such, the notion needs to be interrogated in light of a critical perspective in the hope that this new vantage point can serve as a model or a framework of thinking in complicating and problematizing issues related to differences in not only in races, religions, and ethnicities, but also in English language education.

The idea of multiculturalism in the Indonesian context has been manifested in multicultural education. The inclusion of multiculturalism subject in the school curriculum has been predicated on the assumption that multicultural education is highly germane to pluralistic societies prone to social unrest as it emphasizes the importance of cultural knowledge and the understanding of differences (Sugiharto, 2006, 2009). However, despite the bandwagon enthusiasm in embracing multicultural education, the notion of multiculturalism per se is not well-understood. For most education practitioners the term multicultural is such an abstract construct that it is normatively conjured up as the acknowledgment and appreciation of differences in religions, races, ethnicities, linguistic background, and cultural traditions.

This article argues that the prevailing conception of multiculturalism (as reified in multicultural education) we have glorified is too simplistic, if not naïve. As I have discussed elsewhere (Sugiharto, 2011), the notion of multiculturalism in our context has often been connected and reduced to such well-sounding words as tolerance, respect, and appreciation toward differences in ethnicities, religions, cultures, and languages. I argue here that this simplistic concepttualization is problematic, and as such, needs to be reconceptualized in light of critical theory, in particular, critical multiculturalism. To support this argument I will demonstrate that - through a personal observation in the specific field like English language education in the local context - despite our fetish in championing multicultural education, we are paradoxically discouraging the spirit of multiculturalism. We are instead being constantly enmeshed by the Western hegemonic forces, which suppress our agency and identity. This has been evident in the current English 
language teaching practices and research. Finally, through examples of four revealing case studies of multilingual writers in their search of the politics of identity in academic writing, I suggest that by adopting a critical perspective of multiculturalism, and hence critical multiculturalism (Kubota, 2004), as a framework of thinking, we can help raise teachers' awareness to adopt a critical teaching and research practice that not only values the multiplicity of students' cultures but also resists linguistic and cultural determinism imposed on them.

\section{CRITICAL MULTICULTURALISM: A CRITIQUE OF LIBERAL MULTICULTURALISM}

The appeal of critical theory has stimulated contemporary scholars in the field of pedagogy in general and English language education in particular to attach the label "critical" in their theories. In fact, critical theory has enjoyed profileration in many disciplines such as critical pedagogy (Giroux, 1988). discourse analysis (Fairclough, 1995), critical language testing (Shohamy, 1998), critical applied linguistics (Pennycook, 2001), critical academic writing (Canagarajah, 2002b), critical contrastive rhetoric (Kubota \& Lehner, 2004), and critical multiculturalism (Kubota, 2004).

Just as other theories bearing the label "critical" attempt to challenge the status quo, so does critical multiculturalism. Specifically, critical multiculturalism criticizes the very conception of multiculturalism as appreciation and respect of various forms of differences, which Kubota (2004) calls "liberal multilingualism". This latter type, Kubota argues, uses the notion of multiculturalism as "a taken-forgranted label", which is devoid of a "serious inquiry" into what the notion really means. In addition, cultural differences and diversities as being celebrated in liberal multiculturalism take only superficial aspects of culture such as customs, artifacts, and festivals, so much so that they are "treated in decontextualized and trivialized manners divorced from the everyday life of people and the political struggle to define cultural identity" (p. 35).

Finally, the appreciation of cultural differences presupposes the notion of culture as a stable and homogenous system. Intercultural communication, for example, which is claimed to be able to bridge communication differences, assumes the homogeneity and stability of culture as it seeks unique communication style in each culture (Kubota, 2004, p. 36). Kubota also further argues that because it is influenced by the dominant ideology of individualism and liberal humanism, liberal multiculturalism dismisses issues of power and privilege and is tacitly promoting and disseminating "assimilationist agenda" while maintaining the status quo of the dominant ideology. She says:

...the celebration of both individual differences and cultural differences is in a complicit relationship with the avoidance of power and privilege in creating illusionary equality while maintaining the existing powers that the people on the margins are expected to assimilate (p. 36).

The trouble with the ideology of individualism is that there are many cases that cannot be resolved by resorting to individual perception and behavior, but should be addressed at the collective level. Issues on racism, oppression, and marginalization, for instance, should involve the examination and analysis of humans as a group (e.g., in institutions and society) rather than as an individual.

With its emphasis on the value of cultural differences, liberal multiculturalism has been alleged to have the tendency of "exoticizing and essentializing" ones' culture against another culture. In the field of English language teaching, for example, it is not infrequent to hear the dichotomy "the culture of the Center (referring to the culture of those coming from the inner-circle English) and the culture of Periphery (referring to the culture of those coming from both the outer and expanding-circle English), with the former enjoying the privilege in knowledge construction and production (see Canagarajah, 2002a). In terms of knowledge construction and production, the culture of the former is often regarded as superior, logical, sensible, literate, standard, and rational, while the culture of the latter is essentialized and exoticized as non-sensible, sloppy, non-literate, non-standard and illogical (see also Shin \& Kubota, 2008).

As a possible corrective to these limitations, a critical perspective of multiculturalism can help unravel the causes of the "illusionary equality", interrogates our interests and ideologies in defining culture, and calls into question the assumption of difference and equality strongly held by liberal multiculturalism. Basing its underlying philosophy on critical pedagogy, critical multilingualism problematizes and interrogates this assumption in light of "a critical understanding of culture". It is important to highlight that from the perspective of critical theory, culture is re-conceptualized as a construct which is seen as diverse, fluid, dynamic, and socially, politically and discursively constructed. The changing nature of culture is viewed as inevitable due to "the influence of political, economic, and technological developments as well as domestic and international relations of 
power" (Kubota, 2004, p. 38). The mutability of culture also entails the fact that no culture or language is value-free and absolute; in other words, culture is always value-laden.

In addition, such an important construct as knowledge has been redefined in keeping with the spirit of postpositivist ideology to embrace the inclusiveness of human agency in knowledge construction and production. Canagarajah (2002b) encapsulates this redefinition as follows:

- Knowledge is constructed. Knowledge is entity which exists due to human mediation and involvement. Its existence is imputed to the process of accumulative negotiation with and reconstruction of the changing social context. This emerging view is radically different from the positivistic tradition with holds that knowledge is free of human involvement, universal, absolute, and can be objectively verified in terms of dichotomy correct and incorrect.

- Knowledge is subjective. The involvement of human subjective facets in the process of knowledge construction has now gained legitimacy in the ccontemporary perspectives in science. Specifically, it has been argued that interests, biases, experiences, feelings, imaginations, and predispositions play a siginificant role in our endeavors in explaining phenomena. Subjectivity is now respected as it provides us with the tools to interpret reality. Contrary to traditional viewpoints of knowledge as value-free, this emerging perspective sees knowledge as value-ridden.

- Knowledge is interactive and collaborative. Our interactions of and collaborations with other people play significant roles in the construction and reconstruction of knowledge. Through engagement, constant interchanges, disparity in arguments, transactions, debates and consensus building, knowledge is built up, accumulates, and always undergoes reconstruction. This perspective, however, stands in sharp contrast to the conservative vantage point of knowledge as an individual property.

- Knowledge is contingent and contested. This view assumes the unsteadiness of knowledge and sees it as undergoing changes over time and as getting redefined in light of the emergence of new paradigms. The redefinition of knowledge entails the contestation of knowledge through which communities and groups struggle for gaining the legitimacy of their own knowledge constructs ( pp. 127-129).

The distinctive features of liberal multiculturalism and critical multiculturalism can be encapsulated in the following way: The former stresses "common humanity" and "natural equality" in terms of differences in cultures, races, languages, and genders, with the eventual goal being the celebration of assumed differences and inequalities; by contrast, the latter examines and interrogates these differences by situating them in a specific political and ideological context with the aim being social transformation or change. Furthermore, despite its emphasis on equalities, the former paradoxically favors differences and regards social reality as fixed entities not to be disputed and questioned, let alone being challenged. On the other hand, the latter views such constructs as culture and knowledge as mutable, dynamic, heterogeneous, discursively constructed, contested and implicated in political and historical contexts. Thus, it views culture as "a site of conflict and struggle", which always undergoes a constant state of change. Finally, whereas liberal multiculturalism maintains the establishment, critical multiculturalism challenges it. In other words, it is counter-hegemonic. Obviously, the underlying premises, upon which critical multiculturalism is based, owe very much to poststructuralism and post-modernism constructs, which repudiate truth as an absolute entity and culture as orderly, coherent system. Critical multiculturalism rejects neutrality, but acknowledges culture as a site full of conflict, struggle, and contestation through which discourse is created.

\section{THE PERTINENT PROBLEMS}

One of the persistent obstacles for those who wish to ambitiously promote the well-established notion of liberal multiculturalism concerns the following disconcerting inquiry: Whose cultural model will be used as a 'standard' representation to be emulated and imitated? Although such an inquiry may sound a bit cliché, I feel obliged to replicate it here because it seems that it has been taken for granted in most discussions on multilingualism. Liberal multicultural perspective, with its tendency to view culture as immutable, will likely seek a unitary model of culture - a model which ignores "the political and ideological struggles of power that generate and transform the definition and reification of culture" (Kubota, 2004, p. 39) (Italic added). Such a model, however, has been assumed to be relevant when applied everywhere.

With such a unitary model of culture, it is thus plausible to suspect that the fragility of the notion of culture can be abused by those who want to ambitiously promote multiculturalism as a means of perpetuating 'essentialism and exoticism' in understanding other cultures. Such is unexceptionably a liberal multilingualism perspective. Unless being 
critically interrogated, we cannot expect much from our educational practitioners in their attempts to practice multilingualism as they are working under the fuzzy "paradigm".

Clearly, many of the assumptions underlying liberal multilingualism discussed previously cannot inspire local teachers and students to show resistance (either covert or overt) against the domination of hegemonic ideology prevailing in the English language pedagogy in the local context. With the culture of the center still serving as the gate-keeping function in knowledge construction and production, the possibility is that "the knowledge they (the teachers in the periphery) wish to represent will be distorted, suppressed, or perhaps appropriated according to the terms set by the center" (Canagarajah, 2002b, p. 85). In such a situation it is not impossible that teachers simply conform to the established conventions of the center, rather than "adopt a paradoxical attitude of resisting these conventions" (Canagarajah, 2002b, p. 85).

It is interesting to observe that despite the bandwagon enthusiasm in voicing multicultural education, our education practitioners and scholars are - through their teaching practice and research - ironically promoting the superiority of the established knowledge and culture of the center, legitimizing and furthering its modes of operation in the local contexts. The exultation of the legitimate and superior culture and knowledge has also made education policy makers, teachers and researchers alike exhort people to conform to the established conventions so as to appear 'scientific', 'rational', 'coherent', 'linear, and clear in thinking', as well as 'logical'.

The design of the state's mandated-curriculum for English language teaching (ELT) in Indonesia, for example, lends support to the theoretical framework proposed by scholars from Kachru's Inner Circle. Thus, rather than encouraging the innovative works of the local scholars, the Indonesian Ministry of Education and Culture, which has been sponsoring the making of ELT curriculum in Indonesia, has shown its heavy reliance on the product of a cultural determinism.

Likewise, the reliance on the product of cultural determinism can also be conspicuously seen in classroom teaching practices, especially in the teaching of academic writing. Heavily influenced by the imported writing textbooks, which prescribe the conventions preserved by the Western academic community, teachers continue to exhort their students to one-sidedly conform to the conventions, thus furthering the hegemonic forces of Western ideology (see also Sugiharto, 2007).
Finally, the paradigm of research employed in ELT circles in Indonesia still clings to a positivist philosophy in orientation. In his review of ELT research in the country, Sugiharto (2012) provides evidence of this orientation and concludes that most studies on ELT are formalistic and conformist in their approach, treating texts as rigid, stative, generic, abstract, isolated, product-oriented and detached from their social condition which shapes and is shaped by them (p. 3).

Instead of developing a habit of critically challenging and countering this established knowledge from the local's socio-political and ideological perspectives, the state, local education practitioners and textbook writers and local scholars have helped contribute to the suppression and stigmatization of their local knowledge and their complex agency (Sugiharto, 2013). Moreover, the fetish about cultural determinism has further strengthened the unquestionably authoritative knowledge of the center, and consequently undermined efforts to explore possibilities of localized epistemic practice (Sugiharto, 2011). Probably having no solid 'base knowledge', most teachers and researchers tend to develop a feeling of insecurity if they do not conform to the established conventions set up by the center, fearing that the defiance of these conventions does them more harm than good, as they will eventually be labeled as sloppy, illogical, and irrational.

\section{APPLYING THE PRINCIPLES OF CRITI- CAL MULTICULTURALISM IN ENGLISH ACADEMIC WRITING}

A substantial body of research has been carried out in keeping with the spirit of current rethinking like a critical theory in English language education. In this section, I will present three revealing case studies of multilingual student writers struggling for voice in academic writing in their search of the politics of identity. I am most interested here in describing how these non-native English student writers grappled with the complexities of textual construction in English academic writing in order to achieve academic success. In fact, the efforts these multilingual students made in struggling with the conventions of academic writing reflect the principles of critical multiculturalism.

Related to research on English academic writing, we have seen that in the past decades burgeoning studies investigating how the complex constructs such as identity and agency are manifested through the construction of written texts. One revealing study was done by Sri Lankan sociolinguist Suresh Canagarajah. Situating how texts were constructed in his Sri 
Lankan student's social contexts and borrowing important constructs from poststructuralist theory, Canagarajah (2005) examined students' strategies of negotiating the dominant Western-centric discourse of academic writing. He observed how one of his students managed to negotiate the tension between her home rhetorical tradition and the conventions of academic discourse. Despite working under the pressure of the dominant academic discourse, his student was not diffident to display her own agency and subjectivity in gaining voice and authorship in the academy by appropriating the dominant discourse. Interestingly, this struggle in textual construction results in a creative and hybrid textual realization. The hybrid texts the student produced are actually the products of her effort to infuse her agency (ideology, rhetorical tradition, and cultural modes of thinking) in academic writing.

Another study was carried out by Taiwanese scholar Liu. Liu (2008) investigated how Taiwanese students struggled to gain voice in English academic writing by negotiating academic writing conventions and contextual constrains. The finding of this study revealed a complex relationship between issues of form, content, self and community of writing and the process of negotiation. For example, during negotiations students exhibited resistance against the exhortation of their teacher and struggled to fight for their values and beliefs. They also appropriated the dominant academic discourse in order to suit their purposes and interests in their writing.

Soyoung Baek Burke, a native Korean scholar, investigated how six Korean students at a university in the U.S. constructed their academic writer identities ideationally, interpersonally, and textually. Basing her research on social constructivism and discourse theory, Burke (2010) found that the way the student writers constructed their identities is impinged upon by several factors such as their previous Korean writing practices, privileged academic discourse, marginalized ESL social and linguistic identities, program level, resistance, and blogging. From her findings, Burke concludes that students adopted multiple writer identities, and that these identities were shifted, unstable, and conflictual.

Finally, Sugiharto (2012) examines the construction of one aspect of writing identity known as self in English academic writing. Employing critical academic writing as the theoretical backdrop in his study, Sugiharto reveals a complex process of the construction of self of his three student writers, which includes showing respects to established authorities, depersonalizing knowledge, personalizing knowledge, and using the discursivity and linearity. In this process of the self-construction, he found that the three students displayed their critical voices in negotiating with the relatively fixed conventions of academic writing they were expected to acquire and apply in writing. Quite interestingly, despite pressure to satisfy the academic conventions, the students in many occasions exhibited resistance and instead infused their own voices, albeit sounding less academic and having the risks of being labelled as "deviant" from the academic conventions. Thus, Sugiharto's findings corroborate Burke's study that identities in English academic writing are always unstable, ambivalent, and conflictual, depending on the dynamics of social contexts of writing.

From the perspectives of critical multiculturalism, the hybrid texts produced by the multilingual students in the above studies have their own legitimacy in that their realizations were made possible through constant negotiations and conflicts of human agents who bring their unique socio-cultural repertoires in the process of knowledge constructions and interrogate the commonly accepted conventions by virtue of their specific political, rhetorical, and ideological contexts. In this sense, academic "cultures" are viewed as undergoing continuous mutability or changes and are discursively constructed and reconstructed.

\section{IMPLICATIONS AND CONCLUSION}

The students' construction of voice in English academic writing, as has been demostrated in the above studies, certainly has far-reaching implications for further studies on critical multiculturalism. First, using a critical theory as the backdrop these studies have been able to unravel the students' complex identity and agency manifested by such strategies as resisting and approximating dominant academic discourse. Second, the studies have told us a great deal that the critical perspective, exemplified in the basic tenets of critical multiculturalism, reveals the fact that identity construction is much more intricate than what has been previously assumed.

Thus, if differences in textual realization (e.g., hybrid texts) are understood from the students' ideological, political, and socio-cultural contexts, we can gain a rich perspective of how knowledge is discursively constructed and mediated by these factors. At the same time, we provide the students a space for exploring possibilities for oppositional voices, which has the potential of appropriating the established academic discourse. Clearly, the ideology of individualism as embraced by liberal multilingualism cannot provide a real account of a complex process of knowledge construction which is mediated by equally complex, unpredictable variables. 
The basic tenets of current rethinking like critical multiculturalism can provide the impetus of carrying out research on English language education in the multilingual contexts. Indeed, the surge of interests in the employment of critical theory needs to be commended because it augurs well to the advancement of the field. I have tried in the present article to show the relevance of the principles of critical multiculturalism in English language education in search of the politics of identity. By contextualizing critical multiculturalism in English language education, we can gain genuine insights into how the multiplicity of student's cultures, identities, and agencies is manifested via, among others, the process of textual construction. Furthermore, the reification of the subtle construct of multiculturalism through English language teaching and learning can certainly provide us with a deeper understanding of how one's identity and agency are discursively constructed and how ideological and social variables affect the very process of knowledge construction.

Nevertheless, it is important to note here that adhering to critical theory is not meant to disparage other theories without the label "critical". In a similar vein, we cannot uncritically welcome any theory without interrogating and examining its underlying constructs and ideological orientations. Given that no theoretical constructs and no ideological orientations promoted by any theory (including critical multilingualism) are value-free and reflect objective truth, the inculcation of critical thinking and practice should become the priority in our educational practices if our terminal goal is to encourage teachers to be what Giroux (1988) calls a "transformative intellectual", meaning that

Teachers are not mindless practitioners but informed intellectuals. They are not conformists who simply implement the agendas of others but transformers of social and educational conditions (Canagarajah, 2002b, p. 235).

\section{REFERENCES}

Burke, S. B. (2010). The construction of identity in the academic writing of Korean ESL students: A qualitative study of six Korean students in the U.S. [Unpublished dissertation]. University of Pennsylvania, Pennsylvania.

Canagarajah, A. S. (2002a). A geopolitics of academic writing. Pittsburgh: University of Pittsburgh Press.

Canagarajah, A. S. (2002b). Critical academic writing and multilingual students. Ann Arbor: University of Michigan Press.

Canagarajah, S. (2005). Addressing issues of power and difference in ESL academic writing. In J. Flowerdew \& M. Peacock (Eds.), Research perspectives on English academic purposes (pp. 117-131). Cambridge: Cambridge University Press.

Fairclough, N. (1995). Critical discourse analysis: The critical study of language. London: Longman.

Giroux, H. (1988). Teachers as intellectuals: Toward a critical pedagogy of learning. New York: Bergin and Garvey.

Kubota, R. (2004). Critical multilingualism and second language education. In B. Norton \& $\mathrm{K}$. Toohey (Eds.), Critical pedagogies and language learning (pp. 30-52). Cambridge: Cambridge University Press.

Kubota, R. \& Lehner, A. (2004). Toward critical contrastive rhetoric. Journal of Second Language Writing, 13, 7-28.

Liu, Y. (2008). Taiwanese students' negotiation with academic writing: Becoming "playwright and film directors". Journal of Second Language Writing, 17, 86-101.

Pennycook, A. (2001). Critical applied linguistics: A critical introduction. Mahwah, NJ: Lawrence Erlbaum Associates.

Phillipson, R. (1992). Linguistic Imperialism. Oxford: Oxford University Press.

Shin, H. \& Kubota, R. (2008). Post-colonialism and globalization in language education. In B. Spolsky \& F. M. Hult (Eds.), The handbook of educational linguistics (pp. 206-219). Oxford: Blackwell.

Shohamy, E. (1998). Critical language testing and beyond. Studies in Educational Evaluation, 24, 331-345.

Sugiharto, S. (2006, December 30). Questioning Multicultural Education, The Jakarta Post, p. 6.

Sugiharto, S (2007). New directions in contrastive rhetoric: Some implications for teachers of writing in multilingual contexts. The Journal of ASIA TEFL, 4, 105-122.

Sugiharto, S. (2009, January 22). Multiculturalism in RI: Opportunities and Challanges, The Jakarta Post, p. 6.

Sugiharto, S. (2011, January 15). Oral Tradition and Foucault's Games of Truth, The Jakarta Post, p. 6.

Sugiharto, S (2012). The construction of self in academic writing: A qualitative case study of three Indonesian undergraduate student writers. [Unpublished dissertation]. Atma Jaya Catholic University, Jakarta.

Sugiharto, S. (2013). Disentangling linguistic imperialism in English language education: The Indonesian context. In M. Bigelow \& J. EnnserKananen (Eds.), The handbook of educational linguistics. New York: Routledge. Manuscript in preparation. 